\title{
NÚCLEO FIGURATIVO DA REPRESENTAÇÃO SOCIAL: CONTRIBUIÇÕES PARA A EDUCAÇÃO
}

\author{
RITA DE CÁSSIA PEREIRA LIMA ${ }^{1}$ \\ ORCID: https://orcid.org/0000-0002-3055-4915 \\ PEDRO HUMBERTO FARIA CAMPOS ${ }^{2}$ \\ ORCID: https://orcid.org/0000-0002-0844-8358
}

\begin{abstract}
RESUMO: Este estudo tem como objetivo discutir o "núcleo figurativo", parte integrante da Teoria das Representações Sociais (TRS), fundamentada na Psicologia Social. O foco, aqui, é o campo educacional, na perspectiva de um olhar psicossocial para as relações educativas. O núcleo figurativo é abordado, neste texto, por meio de obras clássicas da TRS, principalmente pelo texto: A psicanálise, sua imagem e seu público, de Serge Moscovici. Avanços posteriores são também considerados, retomando-se os conceitos de "núcleo central" e de "imagem social". A consequência das reflexões apresentadas para o estudo da objetivação da representação social é a necessária e incontornável complementariedade entre essas noções. A título de ilustração, são apresentadas duas pesquisas da área da Educação, nas quais o núcleo figurativo foi condensado em "metáforas", as quais coordenaram os discursos dos grupos que participaram desses estudos. Este estudo propõe que o aprofundamento do núcleo figurativo é uma via fértil para as pesquisas no campo da Educação, principalmente porque permite as relações entre pensamento, práticas sociais e mudanças.
\end{abstract}

Palavras-chave: Núcleo Figurativo, Representações Sociais, Metáforas, Educação

\section{FIGURATIVE NUCLEUS OF SOCIAL REPRESENTATION: CONTRIBUTIONS TO EDUCATION}

\begin{abstract}
This study aims to discuss the "figurative nucleus", which is an integral part of the Theory of Social Representations (SRT), based on Social Psychology. Here the focus is on the educational field, from the perspective of a psychosocial look at the educative relationships. The figurative nucleus is presented, in this text, through the classic works of the SRT, mainly by the text: Psychoanalysis, Its Image and Its Public, by Serge Moscovici. Subsequent advances are also considered, taking up the concepts of "central nucleus" and "social image". The consequence of the presented reflections for the objectification of the social representation study is the necessary and unavoidable complementarity between these notions. As an illustration, two researches in the area of Education are presented, in which the figurative nucleus has been condensed into "metaphors", which have coordinated the speeches of the groups that took part on these studies. This study proposes that the deepening of the figurative nucleus is a fecund way for the studies in
\end{abstract}

\footnotetext{
${ }^{1}$ Universidade Estácio de Sá (Unesa/RJ). Rio de Janeiro-RJ/Brasil E-mail: <ritaplima2008@gmail.com>.

${ }^{2}$ Universidade Estácio de Sá (Unesa/RJ). Rio de Janeiro-RJ/Brasil E-mail: <pedrohumbertosbp@terra.com.br>.
} 
the field of Education, mainly because it allows the relations between thought, social practices and changes.

Keywords: Figurative Nucleus, Social Representations, Metaphors, Education

\section{NÚCLEO FIGURATIVO DE LA REPRESENTACION SOCIAL: CONTRIBUCIONES PARA LA EDUCACIÓN}

RESÚMEN: Este estudio tiene por objetivo discutir el "núcleo figurativo", parte integrante de la Teoría de las Representaciones Sociales (TRS), fundamentada en la Psicología Social. El foco, aquí es el campo educacional, en la perspectiva de una mirada psicosocial para las relaciones educativas. El núcleo figurativo es abordado, en este texto, por medio de obras clásicas da TRS, principalmente por el texto: El psicoanálisis, su imagen y su público de Serge Moscovici. Avances posteriores son también considerados, retomándose los conceptos de "núcleo central" y de "imagen social". La consecuencia de las reflexiones presentadas para el estudio de la objetivación y de la representación social es la necesaria e inevitable complementariedad entre esas nociones. A título de ilustración se presentan dos investigaciones del área Educativa, en las cuales el núcleo figurativo fue condensado en "metáforas", las cuales coordinaron los discursos de los grupos que participaron de esos estudios. Este estudio propone que la profundización del núcleo figurativo es una vía fértil para las investigaciones en el campo de la Educación, fundamentalmente porque permite las relaciones entre pensamiento, prácticas sociales y transformaciones.

Palabras clave: Núcleo Figurativo, Representaciones Sociales, Metáforas, Educación

\section{INTRODUÇÃO}

Autores como Sousa (2002), Sousa, Tavares e Villas Bôas (2009) e Sousa e Villas Bôas (2011, 2011a) fazem referência à expansão da Teoria das Representações Sociais (TRS) no campo educacional, no Brasil, nas últimas décadas, e ao seu potencial para avanços nas pesquisas da área. Essas autoras chamam a atenção para o "olhar psicossocial" da Teoria das Representações Sociais (MOSCOVICI, 1961, 1976, 2012), considerando-o fundamental em estudos sobre temas ligados à Educação, sendo a essência desse "olhar" a relação entre as dimensões psicológica e social que permeiam as interações sociais.

Abdalla e Villas Bôas (2018) destacam que pesquisas embasadas nesse referencial teórico podem provocar mudanças nas práticas educativas, principalmente por privilegiarem elementos simbólicos no estudo de fenômenos sociais, com uma visão crítica e desestabilizadora. Segundo as autoras, diante de um contexto de crise que envolve o papel da escola e dos agentes sociais ligados a ela, o "olhar psicossocial" demanda uma postura epistemológica porque adota a perspectiva de se compreender a mudança social. Ressaltam que, na abordagem moscoviciana, esse "olhar" reflete um modelo triangular em que três elementos são interdependentes: alter-ego-objeto. Nessa interação, o indivíduo/grupo atribui significados a um objeto social na relação com outro sujeito/grupo, ao mesmo tempo que se constitui como sujeito/grupo. Essa pode ser uma interação consensual ou conflituosa, sendo que esta última tem potencial para gerar mudanças.

Compartilhamos a posição das autoras e reforçamos a importância dos estudos das representações sociais (RS) no campo da Educação. Tais representações são vistas como um modo de investigar como se formam opiniões, crenças e valores no pensamento das pessoas, em interação umas com as outras, a respeito de um objeto social que as mobiliza. Desse modo, como se constrói uma visão de mundo quando um objeto emerge socialmente, no campo da Educação, ecoando nas práticas sociais dos grupos envolvidos? As RSs são construções sociocognitivas submetidas a uma 
dupla lógica (cognitiva e social): à influência do contexto discursivo e do contexto social. As RSs expressam o conhecimento do senso comum elaborado e compartilhado sobre um objeto social por grupos em interação, em uma perspectiva dinâmica. Ou seja, as RSs podem ser estáveis, mas também mudar quando situadas em um contexto de lutas, tanto "materiais quanto simbólicas", se tomarmos por referência um "campo de lutas". Partimos do princípio que há representações sociais em luta a respeito de diversos objetos do campo da Educação, que, se desveladas, se tornam compreensíveis e possíveis vias de mudança.

Dentro do campo mais amplo da grande théorie (grande teoria) proposta por Serge Moscovici, neste artigo, procuramos avançar sobre as reflexões que consideramos centrais na abordagem das RSs e que permitem pensar a estabilidade e a mudança de objetos sociais ligados à Educação. Trata-se do "modelo figurativo", ou "esquema figurativo", exposto por Moscovici (1961, 1976, 2012) quando apresentou a TRS. Posteriormente, o autor passou a designá-lo como "núcleo figurativo", terminologia também adotada neste trabalho. O núcleo figurativo é um "esquema" (modelo ou imagem) básico resultante do processo de objetivação, tornando concretos os elementos do objeto, e tem por função guiar as percepções e julgamentos associados ao objeto de representação dentro de uma realidade social construída (JODELET, 1984).

No estudo das RSs da psicanálise elaboradas por diversos grupos na França, em meados da década de 1950, Serge Moscovici refere-se ao "modelo figurativo" apresentando um esquema explicativo da organização psíquica dos participantes de sua pesquisa, no qual quatro elementos são organizados e hierarquizados: "consciente", "inconsciente", "recalque", "complexo". Nesse esquema, o autor mostra que o termo "complexo" ocupa um lugar central na representação social (RS) da psicanálise elaborada pelos sujeitos, visto que modifica o conceito de Complexo de Édipo definido na teoria psicanalítica. Se, nessa teoria, a definição dos cientistas implica um conjunto de desejos, tanto amorosos quanto hostis, que as crianças sentem na relação com seus pais, para os participantes leigos do estudo do autor, a psicanálise teria relação com outro tipo de "complexo", como atributo da pessoa, por exemplo: "complexo de timidez", "complexo de inferioridade". Esse entendimento dos leigos seria uma RS. Foi, assim, lançado um dos fundamentos para se compreender as RSs, enquanto conhecimento do senso comum elaborado por sujeitos/grupos, tendo como parâmetro um conhecimento científico.

De acordo com Moscovici (1976), no esquema que expressa o "modelo figurativo", dois movimentos convergem: a) o da teoria à imagem, quando a concepção científica é confrontada com os valores dos grupos, sendo as apropriações destes feitas de maneira seletiva; b) e o da imagem à construção social da realidade, à medida que a RS não é somente um "duplo" da ciência, mas também "teoria profana" utilizada para classificar pessoas e comportamentos em categorias.

Essa ideia, que aparece desde o estudo seminal de Moscovici (1976), sendo reforçada em textos posteriores (MOSCOVICI, 1983, 2003; JODELET, 1984, 1989, 1989a), supõe que as RSs têm um "núcleo" organizando o pensamento do grupo quando este é mobilizado por um objeto. Defendemos que os estudos da área, para se caracterizarem como pesquisa de RS, precisariam abordar, de algum modo, esse núcleo. Com esse escopo, o objetivo deste artigo é reforçar a relevância e desenvolver reflexões sobre o "núcleo figurativo" em estudos de RS, particularmente no campo educacional. Para tanto, apresentamos o modo como o tema é tratado nos estudos clássicos de Serge Moscovici $(1978 / 2012)^{1}$ e de Denise Jodelet (1989a/2015). Em seguida, indicamos os avanços propostos por Jean-Claude Abric (1976), buscando relacionar o "núcleo central", proposto por esse autor, e o "núcleo figurativo", de Serge Moscovici. O item seguinte deste artigo aborda especialmente as contribuições de Pascal Moliner (1996, 2016), por meio do conceito de "imagem social", que reflete um esquema figurativo da representação social. Por fim, apresentamos os estudos realizados na área da Educação que ilustram a aplicabilidade do "núcleo figurativo" da RS.

\section{O “NÚCLEO FIGURATIVO” EM ESTUDOS DE SERGE MOSCOVICI E DE DENISE JODELET}

Educação em Revista|Belo Horizonte |v.36|e206886|2020 
Duas obras são consideradas fundamentais no campo das RSs, especialmente no Brasil: La psychanalyse, son image, son public, de Serge Moscovici, considerada a obra seminal da teoria, primeira edição publicada na França, em 1961, e em edição resumida, em 1976 (no Brasil, foi publicada a edição completa em 2012, com o título: A psicanálise, sua imagem, e seu público); e outra obra, também considerada de grande importância: Folies et représentations sociales, de Denise Jodelet, publicada na França, em 1989 (a primeira edição foi publicada no Brasil, em 2005, e a segunda, em 2015, com o título: Loucura e representações sociais). Por serem estudos de referência na área, abordaremos o modo como os dois autores se referem ao "modelo" ou "núcleo" figurativo.

Para Moscovici (1978/2012), o modelo figurativo é uma reconstituição que torna as formas abstratas compreensíveis. Ele resulta de uma coordenação que concretiza os termos da representação, não sendo somente uma maneira de ordenar informações. Com base na análise dos dados coletados por meio de "cadernos-questionários", aplicados a grupos diferentes da população francesa, o autor apresenta, por meio de um esquema (Figura 1), a organização psíquica dos participantes de seu estudo no que se refere à psicanálise, já mencionada. Novecentos e cinquenta (950) pessoas pertencentes aos grupos considerados responderam à seguinte questão aberta: "Para você o que é a psicanálise?".

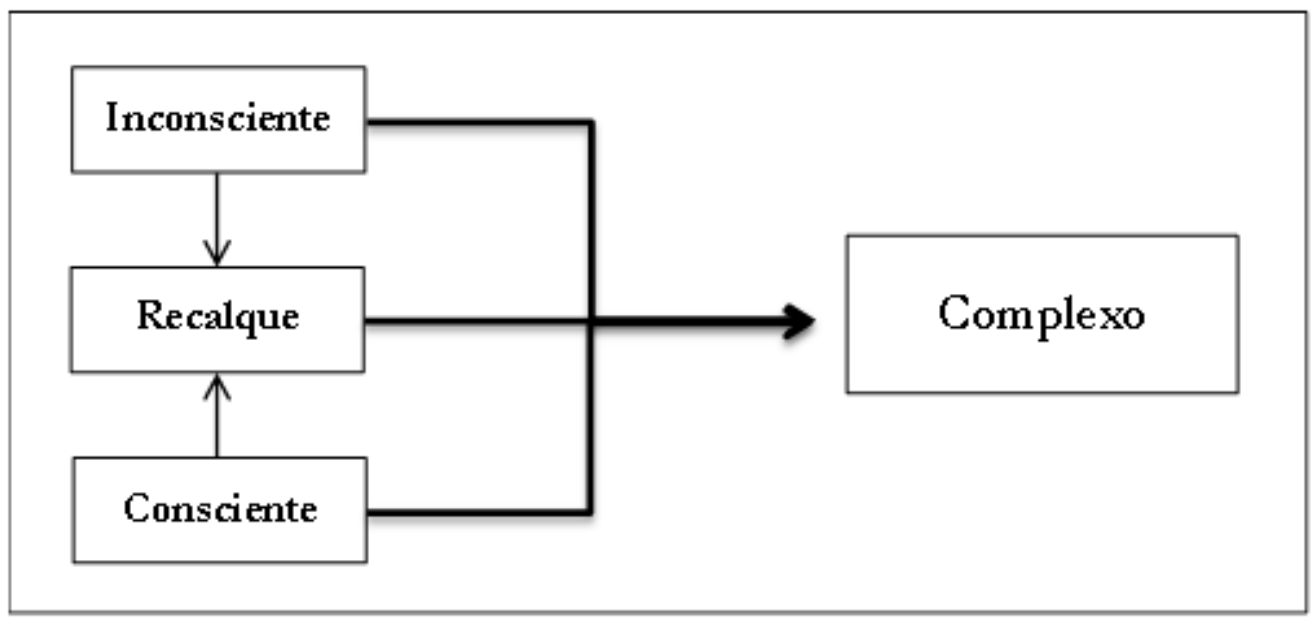

FIGURA 1 - Modelo figurativo da representação social da psicanálise

Fonte: Esquema retirado do texto A psicanálise, sua imagem e seu público, de Moscovici (2012, p. 108).

Moscovici (2012, p. 114) explica os termos desse esquema citando os discursos dos participantes de seu estudo. O "inconsciente", por exemplo, é visto como: a) parte de um todo: "A psicanálise existe para tratar doenças que misturam o subconsciente com o consciente"; b) instância autônoma: "A psicanálise? Trazer o inconsciente para o consciente passando para o préconsciente"; c) forças em conflito - consciente e inconsciente -, em que o conflito personalizado se desenvolve pelo recalque: "Dar às pessoas complexadas o gosto de viver".

O esquema da Figura 1 ilustra, de acordo com Moscovici (2012, p. 108), que as definições expressas mostram uma estrutura da personalidade associada à psicanálise, cuja organização psíquica contém duas partes: "inconsciente e consciente (interior/exterior, escondido/aparente), entre as quais percebemos a ação da pressão de uma contra a outra, ou uma relação de alteridade conflituosa expressa pelas noções de repressão e recalque". Para o autor, o resultado desse funcionamento é o "complexo", que pode ser ilustrado pelos discursos: "Na educação, é preciso evitar a aquisição dos complexos"; "A psicanálise é um tratamento que retira das pessoas o complexo de inferioridade". Para o autor:

Qualificar, por exemplo, uma pessoa como "complexada", “recalcada”, significa associar noções psicanalíticas às operações usuais destinadas a categorizar um gesto ou uma fala, 
a justificar o próprio comportamento ou, em outras ocasiões, a antecipar gestos, falas ou comportamentos. Além disso, significa "ver" nessa pessoa os efeitos de um mecanismo psicológico, a "reconstituir" os diversos cenários das relações com a mãe, o pai, os irmãos, como se as tivéssemos assistido. (MOSCOVICI, 2012, p. 28).

Referindo-se a uma função constante do que é real e do que é pensado, do que é e do que não é científico, o autor propõe a RS como "um corpo organizado de conhecimentos e uma das atividades psíquicas graças aos quais os homens tornam a realidade física e social inteligível, se inserem em um grupo ou relação quotidiana de trocas e liberam os poderes de sua imaginação" (MOSCOVICI, 2012, p. 28).

No modelo figurativo apresentado na Figura 1, que sintetiza como uma teoria científica se transforma em RS, o autor chama a atenção para a supressão da "libido", que, para a psicanálise, é "o que a gravitação universal é para o sistema newtoniano. Ou pelo menos as primeiras esquematizações de Freud (as que marcam presença em nossa sociedade) foram centradas nesse fenômeno fundamental” (MOSCOVICI, 2012, p. 104). O autor continua destacando que:

\footnotetext{
Se eliminamos ou negamos a libido e sua função, epistemológica ou real (sem substituíla por outro princípio), transformamos a teoria psicanalítica num conjunto de relações (interpretações, fenômenos, propriedades) que podem guardar alguma autonomia e, por isso mesmo, integrar-se a outra concepção. (MOSCOVICI, 2012, p. 110).
}

Uma das principais conclusões do autor, baseada no modelo figurativo proposto, é que a teoria psicanalítica é aceitável socialmente, para vários sujeitos pesquisados, se for subtraída dela a teoria da sexualidade. Com essa supressão, o grupo reorganiza seus conceitos com base naqueles que lhe convêm, sendo assim reconstituída a teoria científica com base em valores e regras sociais grupais. Se a sexualidade é desconsiderada, são possíveis as interpretações parciais nas quais um esquema do psiquismo humano pode ser constituído com raízes na teoria psicanalítica, porém sem a "libido". Com base no modelo figurativo, que consideramos central nessa obra que apresenta a TRS, o autor mostra que "a transformação de uma teoria estruturada em um conjunto de relações com autonomia e extensão variáveis é a primeira condição para a constituição de uma representação social" (MOSCOVICI, 2012, p. 111).

A pesquisa de Denise Jodelet (1989/2015), também clássica no âmbito da TRS, teve como objeto as RSs da doença mental e dos doentes mentais, elaboradas por habitantes de Ainayle-Château, comunidade rural francesa que abrigava doentes mentais em suas residências, os quais eram encaminhados e acompanhados por um hospital psiquiátrico. Duas comunidades com essa característica existem na França, desde o final do século XIX, em que doentes mentais permanecem em casas de famílias, onde são abrigados e cuidados, e vivem em liberdade. O estudo de Denise Jodelet foi realizado em uma dessas comunidades, e a autora se interessou principalmente pelo desenvolvimento de um saber espontâneo e pela manutenção de um saber tradicional relacionado à loucura nesse contexto, em que não há difusão de um saber científico unânime.

De acordo com a própria autora, o estudo inspira-se em uma tradição antropológica fecunda para a psicologia social, cujo método se assemelha ao de uma monografia de comunidade, centrado em uma organização social circunscrita. A pesquisa de campo foi desenvolvida durante quatro anos, em que permanências mais curtas, ou mais prolongadas, da autora na comunidade permitiram seu acesso a diferentes esferas e observações das relações que envolviam a vida do doente: espaços públicos (cerimônias, festas, comércio, cafés, igreja, dentre outros) e espaços privados (acolhimento e trabalho nas famílias). Denise Jodelet estudou a instituição psiquiátrica, estabelecendo contato com diferentes informantes e fazendo levantamento de características de cerca de 460 (quatrocentos e sessenta) lares que abrigavam doentes mentais. A autora também realizou entrevistas em profundidade, com três grupos: a) médicos e enfermeiros, em particular "enfermeiros visitantes", encarregados da supervisão dos doentes nas famílias e do controle das alocações; b) informantes escolhidos em função de sua posição chave na sociedade local 
(responsáveis por associações, padres, comerciantes, dentre outros); c) pessoas que abrigavam doentes mentais em suas casas (JODELET, 1986).

Com base na análise dos dados obtidos, Jodelet (2015, p. 365) descreve uma gradação dos estados da doença mental e propõe um esquema tripartite do funcionamento biológico das manifestações ligadas à vida orgânica, social e moral: "cérebro - corpo - nervos", chamado de "núcleo funcional do organismo". A doença é explicada com base em um modelo etiológico que leva em conta o modo como o doente foi atingido (cérebro ou nervos) e a condição em que foi atingido (nascimento ou acidente). Para a autora, esse esquema reflete um "núcleo figurativo", ou uma "nodal representativa", que coloca em jogo a oposição entre "cérebro" e "nervos" no organismo, necessária para a compreensão da realidade humana no campo pesquisado.

Jodelet (2015, p. 293) explica esses dois polos, os quais categorizam o doente "do cérebro" e o doente "dos nervos": a) "cérebro": influência da sociedade, inocência (mal progride de acordo com os malefícios da sociedade), quadro social de equilíbrio e imitação de modelos educativos; b) "nervos": identidade biológica e natureza selvagem, a maldade tem fonte obscura, forças da desordem e impressão contagiosa (animismo). Para a autora, entre esses dois polos há "uma teoria do homem e da sociedade, uma construção racional para distinguir os diversos tipos de doença, usando categorias que a sua experiência e a sua visão de mundo põe à disposição do meio que deve viver com os doentes" (JODELET, 2015, p. 293). A autora faz referência a categorias genéricas observadas nos discursos, tais como: "os tiques, é os nervos"; "os buracos de memória, é o cérebro" (JODELET, 2015, p. 366). Desse modo:

O núcleo funcional "cérebro-nervos-mundo de carne e osso", que explica o funcionamento biopsicológico e os estados patológicos, remete, quando se trata de pensar a etiologia da doença mental, a um triplo apoio no patrimônio cultural do grupo, o seu “já-ali pensado”. (JODELET, 2015, p. 293).

As duas obras mencionadas mostram a relevância do "núcleo figurativo" em pesquisas de RS, principalmente na abordagem de seus processos formadores: a ancoragem e a objetivação. Como afirma Moscovici (2003), a ancoragem é o processo que transforma algo estranho e perturbador no sistema de categorias das(os) pessoas/grupos e o compara com uma categoria que elas(es) consideram apropriada. Isso significa classificar, dar nome a algo. Ainda para o autor, a objetivação é a materialização de uma abstração, característica misteriosa do pensamento e da fala. É reproduzir um conceito em uma imagem. As imagens selecionadas são integradas em um "modelo figurativo", que reproduz um complexo de ideias.

Desse modo, o modelo figurativo proposto por Moscovici (1976/2012), em La psychanalyse, son image, son public, ilustra um esquema conceitual que torna a psicanálise real, concreta, uma imagem substituída por sua contrapartida material, expondo a objetivação: "As palavras 'complexo' e 'recalque', investidas de novo poder, designam manifestações ostensivas do real" (MOSCOVICI, 2012, p. 101, grifos do autor). Assim, pode-se "reconhecer os 'complexos' de um indivíduo como se fossem atributos da sua pessoa; sem que, no entanto, esse reconhecimento esteja associado à psicanálise" (MOSCOVICI, 2012, p. 101, grifo do autor). Ainda segundo o autor: “A lenta assimilação da psicanálise pelo corpo social e a influência dos valores de referência sobre sua evolução se relacionam com a ancoragem" (MOSCOVICI, 2012, p. 100). No "esquema figurativo", a figura (imagem) do objeto social é, ao mesmo tempo, imagem mental, a qual concretiza o objeto,

e "signo", o qual funciona como operador conceitual que permite "pensar" o objeto (discutir, expressar, negociar significados), enfim, permite "comunicar".

\section{RELAÇÕES ENTRE O NÚCLEO FIGURATIVO (NF) E NÚCLEO CENTRAL (NC)}

Abric (1976) desenvolve a ideia de Moscovici (1976/2012) quanto à estrutura de uma RS ter dupla natureza, a figurativa e a simbólica. De acordo com Abric (1976), as RSs constituem- 
se de um conjunto de informações, de crenças, de opiniões e de atitudes a respeito de um objeto social. Em torno desse objeto representado pelo sujeito/grupo, existem elementos organizados que se estruturam e se constituem em um sistema sociocognitivo.

Em seu livro Coopération, compétition et représentations sociales, Abric (1987) retoma sua tese de 1976, acerca da determinação das práticas pelas representações, com base no estudo experimental da situação de jogo. Nessa situação, o sujeito constrói um "sistema" com um conjunto de representações, como as: da natureza do jogo em questão, competitivo ou colaborativo; do parceiro com quem interage, colega de universidade, professor, máquina ou outro; de si mesmo, seja em termos de personalidade ou de categoria social; enfim, também uma representação do ambiente imediato. Nessa retomada, alguns elementos representacionais têm papel organizador, ou seja, central na interpretação da própria situação, na avaliação dos elementos representacionais em jogo e na orientação das condutas. Assim, introduz o conceito de "núcleo central", como um conjunto de elementos simbólicos que tem papel preponderante na visão de mundo formulada pelos sujeitos. O autor inspirou-se no conceito de "núcleo causal", ou "núcleo duro", de Heider (1927), a propósito dos processos de atribuição.

O que nos interessa é que Abric (1987) apresenta a visão da gênese das representações a partir da obra de Serge Moscovici. Quatro fases são discutidas: a) na primeira, com o título Do objeto ao modelo figurativo, uma imagem é produzida com base nos processos cognitivos de descontextualização e seleção das informações originais sobre o objeto, formando um "modelo figurativo", ou "núcleo imagístico", muito simples, concreto e coerente; b) na segunda fase, Do modelo figurativo ao instrumento de categorização, o modelo constituído ganha estatuto de evidência, toma valor de senso comum, ou seja, de imagem consensual no grupo. Esse "núcleo imagístico" vai determinar a relação com o próprio objeto, fornecendo um quadro geral de interpretação, e guiar as percepções e julgamentos, cumprindo, desse modo, a função de "categorizar". Todos os objetos materiais, eventos e atos associados ao objeto social, serão alvo de um processo de classificação, de modo a permitir a constituição de uma nova e complexa "categoria social" cujo referente é o objeto social em questão; c) na terceira fase, intitulada Do instrumento de categorização ao modelo ativo, a representação elabora-se como sistema coerente e adaptativo, tendo um "núcleo imagístico" e um "sistema de categorização" estabelecidos e estabilizados, e esse conjunto (imagem e sistema) tem por função organizar a visão do mundo social em relação ao objeto, assegurando um significado às informações e aos eventos do ambiente, além de orientar as condutas; d) por fim, na quarta fase, A representação, os três componentes da representação, essenciais para assegurar sua funcionalidade, são constituídos e finalizados: um sistema de interpretação, um sistema de categorização e uma linguagem específica. Para dar sustentação a essas "funções" complexas, a representação torna-se, ela mesma, um sistema complexo cujo núcleo não poderia ser mais um "simples núcleo imagístico".

Dessa visão dinâmica, baseada na proposta de Serge Moscovici, podemos tirar duas consequências: 1) o processo de objetivação começa produzindo uma imagem básica, o "modelo figurativo", mas não se estanca mais, pois esse modelo guia a mudança da representação de uma "simples imagem" concreta e naturalizada, para um complexo sistema de gestão da relação entre sujeito e grupo, envolvendo o objeto específico da RS e o contexto sócio-histórico, tanto em sua dimensão social (outros grupos e instituições) quanto em sua dimensão cultural ou simbólica; 2) em uma concepção mais "universal" (BILLIG, 1991) das RSs (como conhecimento do senso comum, como formação simbólica da cultura, como elemento do imaginário social, saber social, sem especificar a natureza mais grupal do sujeito e sem abordar seu caráter consensual), algumas representações teriam um "núcleo figurativo" sem necessariamente ter um núcleo central; em revanche, tratando de uma concepção mais singular (BILLIG, 1991), como um sistema organizado e estabilizado que dá conta do consenso em um grupo, as RSs, em sentido próprio, com "campo do objeto social" bem delimitado (MOSCOVICI, 1976), teriam um "núcleo central", e o "núcleo figurativo" seria uma subparte, ou uma subestruturação, uma reorganização com parte dos elementos centrais que se expressariam diretamente em imagens visuais e linguísticas ("icônicas"), para cumprir duas funções: "figurar" e "mobilizar". 
Outro aspecto ainda relevante refere-se à questão da ação, em última instância, das práticas sociais. O "núcleo figurativo" permite a formação de um sistema de categorização. Em paralelo, a formação desse mesmo sistema de categorização também é direcionada pela própria utilidade social do objeto, que orienta o processo de ancoragem. Ressalta-se que a utilidade social não vai se constituindo no sistema cognitivo de um grupo como fruto de reflexão abstrata sobre o objeto, mas como uma série de "esquemas" ações-trocas comunicativas-reflexões, que, por sua vez, são validadas, ou não, coletivamente/grupalmente. Isso reencontra a visão das RSs como um "corpus" de conhecimentos fundados sobre tradições partilhadas, enriquecidos pelas experiências, que nunca cessam de se renovar, e "sacramentados pelas práticas" (MOSCOVICI; HEWSTONE, 1984; MOLINER, 1996).

Vários textos (JODELET, 1984, 1986, 1989, 1989a; ABRIC, 1987, 1989; BONARDI; ROUSSIAU, 1999; ELEJABARRIETA, 1996), posteriores à obra seminal de Moscovici (1976), apresentam convergência no reconhecimento do processo de gênese das RSs e quanto ao papel desempenhado pelo "esquema figurativo". Contudo, parecem também recobrir o conceito de "núcleo figurativo" em uma densa nuvem: o conceito vai gradativamente perdendo espaço, ou aparece, sem maiores explicações, associado ao conceito de "núcleo central". Para introduzir esta seção do artigo, será útil indicar, desde já, que o problema que preside essa discussão, para nós, é o de como e por que estudar a objetivação, de tal modo que a diferença entre o "núcleo figurativo" e o "núcleo central" se torna uma falsa questão.

Em vários textos publicados entre 1976 e 1999, período que, com pequena margem histórica, pode ser considerado como de expansão e consolidação da TRS, ao se discutir a gênese das RSs, três noções parecem se alternar (às vezes aparecendo juntas): o "núcleo imagístico" (noyan imageant), o "núcleo estruturante" (associado tanto ao "esquema" quanto ao "núcleo" figurativo) e o "núcleo estruturado" (que ora aparece como "núcleo figurativo", mas com maior frequência, como "núcleo central"). No caso do núcleo central, as publicações de pesquisadores associados à abordagem estrutural apresentam um esforço sistemático em teorizar suas funções na representação estruturada (ABRIC, 1989, 1994; FLAMENT, 1989, 1994; MOLINER, 1992, 1994; RATEAU et al, 2012; ROUQUETTE; FLAMENT, 2003).

Jodelet (1984) destaca três fases da objetivação: a seleção e descontextualização; a formação de um "núcleo figurativo", que é uma estrutura imagística que reproduz uma estrutura conceitual; e, por fim, a naturalização. Nesse texto, uma primeira aproximação com o núcleo central é anunciada: "Esta estrutura imagística se revela, em uma série de experiências, ser o núcleo duro e estável das representações [...]" (ABRIC, 1983 apud JODELET, 1984, p. 369). Assim, é reforçado o caráter de núcleo que responde, ao mesmo tempo, como imagem e conceito. Tem-se aí a ideia de que o estudo do núcleo figurativo é necessário ou imprescindível para o estudo da objetivação:

A estabilidade do núcleo figurativo, a materialização, a especialização de seus elementos lhes confere o estatuto de quadro e de instrumento para orientar as percepções e os julgamentos em uma realidade socialmente construída. Ele (o núcleo figurativo) dá as ferramentas para a ancoragem, segundo processo da representação social. (JODELET, 1984, p. 371).

Apesar da ênfase inicial (MOSCOVICI; HEWSTONE 1984; JODELET, 1984, 1989a), o conceito parece, progressivamente, "entrar em desuso", sem ser contestado, em prol de argumentações mais vagas, segundo as quais as RSs têm uma estrutura (sem precisar qual ou quais atributos específicos ou funções dessa estrutura), têm um "modelo básico", até um "núcleo"; falarse-á mais frequentemente em imaginário (APOSTOLIDIS, 2002; ARRUDA, 2002), em mito (KALAMPALIKIS, 2002) ou simplesmente "crenças" (APOSTOLIDIS, 2002). Jodelet (1989) refere-se à "modelização das representações", ao "campo estruturado" e ao "núcleo estruturante", retomando a objetivação em três fases, segundo Serge Moscovici, em termos de: construção seletiva, "esquematização estruturante" e naturalização. Aqui, é reforçada a ideia de um núcleo que participa/conduz o processo de formação (gênese e estruturação) das RSs. Em outro texto, Jodelet 
(1989a) destaca o que chama de "núcleo funcional do organismo" (já mencionado), que remete ao conceito de "núcleo figurativo", contudo sem reforçar o conceito em si.

De um lado, a noção de "esquema figurativo" encontra-se bem constituída no estudo da gênese das RSs, como transformação icônica que materializa (pela seleção/construção de uma imagem) o objeto de RS (MOSCOVICI, 1984, 1998; BONARDI; ROUSSIAU, 1999) e suas funções. Segundo Elejabarrieta (1996, p. 143): "Esta simplificação em uma imagem permite conversar e assim compreender de modo mais simples as coisas, os outros e nós mesmos".

De outro lado, podem-se observar poucos estudos empíricos estudando a objetivação pela via do núcleo figurativo. A partir de meados dos anos 1990, convencionou-se, no Brasil, chamar a abordagem estabelecida por Denise Jodelet de "abordagem processual", cuja denominação viria do fato de se interessar/focalizar pelo estudo dos processos básicos, a objetivação e a ancoragem, na gênese das RSs. Porém, isso contrasta-se, fortemente, com os usos de pesquisas (estratégias) feitas por alguns pesquisadores próximos a essa tradição, que buscaram sustentação em conceitos como imaginário, mito ou crenças. A implicação de tais escolhas é que, nessas pesquisas, o estudo do núcleo figurativo não é concebido como essencial ao estudo da objetivação. Os interesses de pesquisa que vão se concretizando realçam o dilema apontado por Billig (1991), entre uma concepção mais específica das RSs, como conhecimentos estruturados, em relação direta com as práticas e a identidade, portanto dotadas de núcleo, seja este visto como figurativo ou central, e uma concepção mais genérica das RSs, como conhecimentos sociais, como formações simbólicas da cultura, enfim, como partes do imaginário social, ou como partes de um mito ou conjunto de crenças. Quando Billig (1991) apresenta sua crítica, ela não se dirige a nenhuma abordagem em particular, mas aos estudos de representação sem estudo da objetivação, ou seja, sem identificação de núcleo ou de organização das representações.

Esse debate toma forma na atualidade, na redefinição proposta por Kalampalikis e Apostolidis (2016) da abordagem como "sociogenética". Nessa "atualização", os autores colocam, em destaque, a vontade de estudar a formação e o funcionamento das representações nos sujeitos sociais, buscando compreender a relação delas com sua integração com os elementos sociais e culturais que formam o universo de referência, a partir do qual os sujeitos vão construir suas representações. O plurimetodologismo é preconizado para cumprir os objetivos, ou seja, para estudar a sociogênese das representações. Destaca-se ainda que, nessa atualização, não há priorização do estudo da objetivação, nem menção ao conceito de núcleo figurativo. Devemos reconhecer que, na prática de pesquisa e dentro da premissa plurimetodológica, alguns estudos combinam a identificação do núcleo central com o enfoque sociogenético. O que fica em aberto é se o estudo das RSs na abordagem sociogenética (ou processual) não considera mais necessário o estudo da objetivação, ou se é possível conhecer a objetivação sem passar por um núcleo.

Do nosso ponto de vista, não é necessário se abdicar do conceito de "núcleo figurativo" para estudar o imaginário social, os mitos, os valores e as normas sociais, ou mesmo a ideologia, no campo da TRS. Um estudo clássico é o de Chombart-de-Lauwe $(1971,1986)$ sobre as RSs de infância. Em um vasto conjunto de pesquisas empíricas, essa autora parte do imaginário social, identifica a RS a partir desse imaginário e afirma que a RS da infância tem um "núcleo central". Os estudos da autora apontam como essas RSs vão ganhando valor de mito e indicam um funcionamento "mítico". A articulação entre os conceitos de imaginário social, RS e mito é possível uma vez que se delimite a especificidade das próprias RSs através da identificação de um núcleo, sobre o qual já se pode observar as influências dos trabalhos de Abric (1976, 1987), pois é nominado como núcleo central.

\section{IMAGEM SOCIAL E A "FUNÇÃO FIGURATIVA" NO NÚCLEO DAS REPRESENTAÇÕES SOCIAIS}

Moliner (1996) propõe que a imagem mental, que se expressa em um "esquema figurativo", aproxima-se da "imagem social”, visto que a elaboração desta última é determinada por 
fatores coletivos. Para o autor, esse é um momento privilegiado do processo de representação. Moliner (2016) destaca as distinções entre "imagens gráficas e óticas" como sendo objetos presentes no meio exterior aos sujeitos, e entre "imagens perceptuais, mentais e verbais" como pertencentes ao universo cognitivo do sujeito, sem necessidade da presença física do objeto. Essa ideia supõe a construção de uma imagem verbalizada e/ou situada em um contexto psicossocial quando o objeto de representação está ausente fisicamente. Se a imagem se expressa em um "esquema", podemos dizer que ela pode revelar o "núcleo figurativo" da RS:

\footnotetext{
$\mathrm{Na}$ origem de toda representação, vamos encontrar um processo de objetivação que, lembremos, consiste em vincular noções abstratas a objetos concretos e diretamente perceptíveis. Uma vez objetivadas, essas noções poderão ser agenciadas em um "esquema figurativo" que constitui uma forma perceptível e natural do objeto de representação. É a partir dessa forma, que é inicialmente uma imagem mental, que vai se constituir a representação social. (MOLINER, 1996, p. 149).
}

Moliner $(1996,2016)$ procura sintetizar três funções da imagem em uma relação de comunicação: mostrar, sugerir e "induzir" (montrer, suggérer, entraîner). Sem modificar significativamente a essência dessa síntese analítica proposta pelo autor, propomos restringir sua direção acoplando-lhe novos verbos: mostrar - designar; sugerir - argumentar; "induzir" mobilizar. A diferença entre a segunda e a terceira situa-se nas condições para engendrar a realização de atos.

Assim, a produção, ou ativação, de imagens (iconográficas e "figuras de linguagem") associadas a crenças estruturadas de origem social (categorias, estereótipos, protótipos ou RSs) resulta na mise-en-marche (no início) de uma ou de todas essas funções. Isso encontra-se com a afirmação de que as metáforas (figuras de linguagem dominantes na linguagem cotidiana, nas conversações) também servem para argumentar (convencer) e/ou mobilizar (BILLIG, 1996; BOUDON, 1990).

Destacamos ainda que a função de "mostrar", por banal que pareça, não é uma simples indicação, ou sinalização. É a função mais frágil nas imagens sociais (recordando que, ao situarmos a imagem como social, implicamos sua inscrição em uma relação de comunicação), pois sua exatidão e/ou direcionalidade em relação ao objeto dependem de saturação cultural, o que provoca, ou permite, a particularização pela falta de controle dos elementos semióticos presentes na própria imagem. Ainda, como alerta Moliner (2016), por trás (na verdade, por dentro) da imagem encontrase uma intencionalidade daquele que produz a imagem, a qual, por sua vez, raramente se dá como relação revelada, explícita, representação/referência.

Tanto no caso das categorias sociais (com seus "protótipos") e dos estereótipos quanto no caso das RSs com seu núcleo figurativo, uma característica fundamental dessas imagens-bases é que elas podem substituir o objeto diretamente e permitem o reconhecimento quase imediato do objeto (MOLINER, 1996). Nas relações de comunicação, essas imagens básicas cumprem três funções: a) apontam para o objeto, indicam, mostram, "representam" o objeto; b) ativam um processo de sugestão, de fato um processo de "influência social", ou seja, marcam uma posição e sugerem a adesão a essa posição em relação ao objeto, nesse sentido, induzem, ou preparam, os julgamentos; c) ativam emoções, preparando para a ação e/ou eliciando afetos em direção aos valores do grupo (MOLINER, 2016). Pode-se acrescentar que as imagens remetem, para quem as reconhece como signos de um objeto específico, a uma identidade com relação a esse mesmo objeto.

A insuficiência das imagens está na sua incapacidade de mostrar, ou fazer aparecer, a "significação plena" de uma RS. Primeiro, porque falta às imagens uma função prescritiva (MOLINER, 2016); segundo, porque, para ser compreendida, toda imagem, quando situada em uma troca comunicativa, solicita um sistema de decodificação sustentado por conhecimentos anteriores, saberes pré-existentes (ECO, 1988; BARTHES, 1985). Em suma, quando um indivíduo pensa o objeto, ou se refere a ele, dentro de seu grupo identitário, a imagem básica desse objeto 
(no nosso caso, o "núcleo figurativo") basta para contextualizar as trocas, as conversas e os atos. Porém, em uma relação de interlocução com um "outro" (que necessita ser reconhecido como ingroup, ou como outgroup, ou seja, como um "nós", ou como um "eles") faz-se necessário ancorar as imagens em jogo em sistemas de significação previamente estabelecidos. O "núcleo figurativo", para fazer sentido e exercer seus efeitos de signo consensual, para se encontrar seu significado, solicita ser "encaixado" em sistemas semióticos. O "núcleo central", por sua vez, é um sistema semiótico organizado, cognitiva e afetivamente organizador das leituras das situações e da orientação das práticas.

Um caminho para avançarmos nesse debate é encontrado no alerta de Elejabarrieta (1996, p. 143, grifo nosso):

O processo de objetivação, quando é exclusivamente apreendido pelas suas fases de transformação icônica e de naturalização, deve ser manipulado com precaução. Se esta apreensão permite descrever os efeitos do processo de objetivação, e isto de modo geral, ela não permite de modo algum enunciar as características dos processos pelos quais ele funciona.

Sabe-se que a objetivação é um processo dinâmico, e isso sem nenhuma contradição com as formulações originais (MOSCOVICI, 1976), não intervindo somente no momento da gênese de uma representação. A isso soma-se o alerta acima (ELEJABARRIETA, 1996), levandonos a duas questões inesperadas: se estamos falando de "núcleo figurativo", que papel ele teria no funcionamento de uma RS constituída?; suas funções seriam as mesmas do núcleo central, tornando os conceitos de NF e NC intercambiáveis?.

A perspectiva de uma assimilação simples e automática está, há muito tempo, descartada. Como lembram Bonardi e Roussiau (1999), Jean-Claude Abric valoriza o aspecto do conteúdo em si e das relações entre os elementos, realizando, assim, uma transposição do núcleo figurativo, com transformações do "aspecto processual ao conteúdo representacional". De fato, tanto a coerência interna (que assegura a estabilidade) quanto a dimensão funcional (vínculo direto e prescritivo) das práticas, que são funções do núcleo central, não podem ser atributos de uma imagem (MOLINER, 2016), ou de um "núcleo imagístico".

Após realçar as funções que são próprias às imagens e o papel da linguagem figurativa no pensamento e na comunicação cotidianos, retomamos prováveis as relações entre o núcleo central e o núcleo figurativo, tomando por base as funções que um núcleo deve ter: de assegurar a significação do todo (e a especificidade do objeto no universo cultural) e de gerenciar sua organização (ABRIC, 1994). Contudo, algo nessa "estrutura", ou sistema, chamado de "núcleo central", deve ter por objetivo organizar as funções de imagem básica (indicar, sugestionar, mobilizar), as quais são mais ligadas aos valores, à afetividade e à comunicação cotidiana. Dito de outro modo, muito provavelmente, ao menos um dos elementos do núcleo central evoca, emula ou elicia uma imagem básica, o núcleo figurativo. Desse modo, reforça-se a formulação de Moscovici (2012), segundo a qual a representação tem uma "dupla face": "simbólica" (no sentido da significação, como um "quase-conceito" do objeto) e "figurativa". Essas duas faces não são desconexas, assim como os núcleos figurativo e central também não são desconexos: nem o núcleo figurativo é imagem pura do objeto, pois, ao vermos os exemplos estudados por Moscovici (2012) e Jodelet (2015), podemos afirmar que já são como pré-estruturas de significação, fortemente marcadas pelos valores, afetos e experiências; nem o núcleo central é pura estrutura cognitiva, sem relação com os valores, afetos e experiências. Ao contrário, existem pesquisas que fornecem fortes indícios de que o núcleo central é responsável pela organização das cargas afetivas.

Uma tentativa de articular a dimensão dos valores e expectativas ao núcleo central foi idealizada por Moliner (1995, 1995a), através do que ele chamou, naquele período, de "função atribuitiva". Essa teorização iria avançar depois com seus estudos sobre a imagem social (MOLINER, 1996, 2016), os quais nos inspiraram a revalorização do núcleo figurativo. A hipótese do núcleo figurativo como um esquema imagético vinculado ao núcleo central deve ser testada. 
Porém, no atual momento de nossas reflexões, essa hipótese parece-nos bastante frutífera. De modo amplo, a categoria existente de um objeto, que corresponde ao seu conceito na língua, não elimina a produção de novas imagens. Ao contrário, é a contínua e rica incorporação cotidiana de novas imagens que enriquece e transforma os conceitos; tanto as línguas quanto as representações não são imutáveis.

Estudando o "núcleo figurativo", podemos nos aproximar dos valores e cargas afetivas ligadas aos objetos, bem como ter uma porta para identificar tanto as tensões sociais que atingem o grupo e o objeto quanto os processos de transformação das práticas e das representações.

Podemos dizer que o "núcleo figurativo" tem valor de uma metáfora viva (ou um conjunto bem restrito de metáforas) e consensual, uma vez que, sempre que se evocada uma metáfora, é necessário evocar, como contingência, o contexto das relações semióticas em torno do "objeto" que marcam os termos da metáfora (contexto que ativa os processos de simbolização dos ícones); porém, e mais além, há sempre um terceiro termo elipsado, posto que a metáfora é também, simultaneamente, um signo do eu em relação ao objeto. As metáforas que condensam um discurso sobre um objeto social representado são, também, imagens de um "nós" (grupo) em comparação com outras imagens possíveis do objeto, as quais, por sua vez, são estrangeiras ao grupo.

\section{O ESTUDO DO NÚCLEO FIGURATIVO POR METÁFORAS: DOIS EXEMPLOS NO CAMPO DA EDUCAÇÃO}

A título ilustrativo, apresentamos dois exemplos de pesquisas sobre o "núcleo figurativo" por metáfora na área da Educação. Consideramos relevante exemplificar, com intenção de oferecer elementos para se pensar em um modo de operacionalizar parte das concepções teóricas apresentadas, anteriormente, sobre o núcleo figurativo. Tomamos como referência uma tese de doutorado (SANTOS, 2016) e uma dissertação de mestrado (LOPES, 2017) que permitem essas reflexões. Ambas as pesquisas basearam-se na relação entre o núcleo figurativo e as figuras de pensamento, particularmente as metáforas (MAZZOTTI, 1998), as quais condensam significados sobre o objeto social representado. Podemos perceber, assim, a materialização de uma abstração, a reprodução de um conceito em uma imagem, conforme processo de objetivação proposto por Moscovici (2003).

Considerando a imagem verbalizada, ou a "palavra situada" (MAZZOTTI, 2016), os estudos de Mazzotti $(1998,2003)$ contribuem para pensar o conceito de "núcleo figurativo" no campo das RSs. Para o autor, esse núcleo é constituído por figuras de pensamento, sobretudo metáforas, que coordenam e organizam os discursos dos sujeitos/grupos. Ao analisar essas figuras, o autor propõe que é possível compreender os elementos da representação e como eles se organizam nos discursos expressos pelos sujeitos.

Para alcançar seus resultados, as duas pesquisas expostas utilizaram, em suas metodologias, a técnica de "indução de metáforas", por meio das questões: "Se tal objeto pudesse ser outra coisa, o que seria?; Por quê?” (ANDRADE, 2007). Esse procedimento contribui para que o sujeito desloque o discurso formal para o campo informal e coloquial de sua fala. Como afirmam Lakoff e Johnson (2002, p. 45):

“[...] a metáfora está infiltrada na vida cotidiana, não somente na linguagem, mas também no pensamento e na ação. Nosso sistema conceptual ordinário, em termos do qual não só pensamos, mas também agimos, é fundamentalmente metafórico por natureza".

Desse modo, associada a outras metodologias, a metáfora pode reforçar pistas para o núcleo figurativo em estudos de RS. Nosso objetivo aqui não é descrever detalhadamente as duas pesquisas, mas as tomar como ilustrações para melhor compreensão do núcleo figurativo.

Santos (2016) propôs-se a investigar as RSs de Unidade de Polícia Pacificadora (UPP) construídas por professores do Ensino Fundamental de escolas do Rio de Janeiro, no Brasil. Como 
metodologia de coleta de dados, foram utilizadas as entrevistas semidirigidas e o grupo focal. No roteiro das entrevistas, foram colocadas duas questões específicas: se a UPP pudesse ser outra coisa (por exemplo, um animal, um vegetal, um mineral), que coisa seria, e por quê?; se você fosse governador do Estado do Rio de Janeiro, o que faria em relação à UPP?.

Será apresentada, em seguida, a análise das entrevistas feitas com professores de uma das escolas investigadas. O material discursivo foi analisado com apoio da análise temática (BARDIN, 2000), indicando as seguintes categorias principais, seguidas de exemplos das falas dos professores: a) Violência no Rio: "Eu temo vivenciar tiroteio na rua, tenho muito medo mesmo"; "Eu sinceramente me sinto muito assustada. Antigamente, eu andava pelo Rio de Janeiro tranquilamente, mas agora não acontece"; b) UPP em seus aspectos gerais: "Necessário e imprescindível é a necessidade da participação de outros Órgãos do Estado, a polícia sozinha, a UPP, não vai resolver o problema da violência nessas comunidades. É fundamental que haja a participação da Secretaria de Obras, de Habitação, de Infraestrutura, Assistência Social, enfim, Educação, Saúde.”; c) UPP próxima à escola: “Ah eu me sinto mais segura.”, "Foi uma mudança na qualidade de vida da escola e minha, impressionante. A UPP foi pra mim, assim, qualidade de vida. Eu já estava a ponto de desenvolver uma síndrome do pânico.", "Acho que ela altera num sentido talvez mais de abstrato, de paz, de você ter tranquilidade de realizar o seu trabalho.".

Essa análise de conteúdo foi complementada e fortalecida pela questão: "Se você fosse governador do Estado do Rio de Janeiro, o que faria em relação à UPP?". Alguns exemplos de respostas são: "Eu acho que essa relação da UPP tem que estar mais próxima à comunidade. Não só como presença física policial, pra isso ser um sucesso tem que vir a reboque toda a parte de educação, saúde, de envolvimento com a comunidade, se não passa a ser um inimigo."; "Fazia melhora da formação do policial que está ali e as melhorias de ação social. Tem que vir acompanhada de ação social.”.

Enfim, a questão de "indução de metáforas" consolidou a análise anterior e expressou o pensamento do grupo em relação à UPP, refletindo suas experiências sociais e culturais. Alguns exemplos de metáforas foram: a) Cão de Guarda: "Pra guardar, pra cuidar, pra proteger, né? Deveria ser. Eu acho até que tem lugares que deve ser.", "Por que ele estaria me guardando?", "Porque está ali pra resguardar a paz das pessoas que querem, isso aí seria pelo menos o objetivo da UPP né, manter a paz no local e não deixar que nada atrapalhe."; b) Onça: "Acho que de alguma forma eles tem que estar ali, antenados com que pode acontecer.", "Alguma coisa assim que olhasse e amedrontasse. Dar proteção ao aluno e assustasse o bandido."; c) Leão: "Porque tem essas questões do guardar, do proteger, mas que também, que fere, pra defender e guardar é capaz de atacar.".

Figura 2:

Com base no conjunto da análise, foi possível propor o núcleo figurativo exposto na 


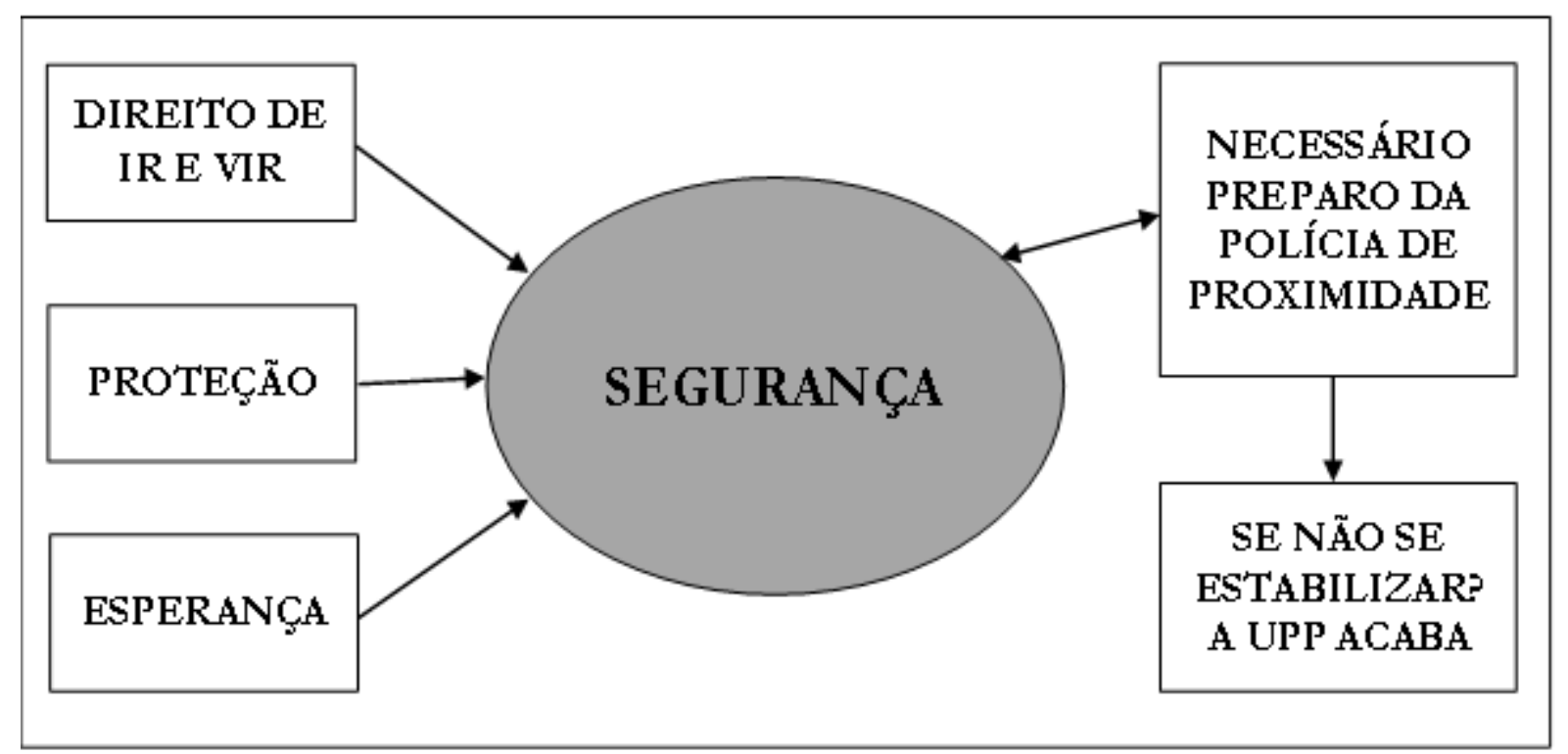

FIGURA 2 - Núcleo figurativo da representação social de UPP por professores do Ensino Fundamental

A Figura 2 indica a objetivação da RS da UPP para os professores, no que se refere ao termo "segurança", assim explicado: o grupo de professores sente-se mais seguro com uma base da UPP em frente à escola, possibilitando o "direito de ir e vir" de quem frequenta a instituição escolar e trazendo "proteção" para a escola e "esperança" em relação ao enfrentamento da violência na região e no Rio de Janeiro. Porém, ainda é necessário um maior preparo da polícia de proximidade para garantir a estabilidade da UPP. O recurso da "indução de metáforas" contribuiu para uma melhor compreensão da organização do discurso do grupo a respeito desse objeto. Analogias com animais, como "cão de guarda", "onça" e "leão", podem assegurar o núcleo "segurança", com o sentido de "proteção" expresso nos discursos, visto como necessário para o trabalho realizado na escola.

O estudo de Lopes (2017) com crianças que frequentavam as "classes de aceleração" (classes especiais para crianças em defasagem de idade/série) teve por objetivo estudar as RSs de escola e da própria "classe de aceleração". Em uma primeira fase, foram conduzidas duas entrevistas coletivas, com apresentação de material projetivo (leitura de uma poesia e de um livro infanto-juvenil, ambas as leituras referindo-se à vida de crianças na escola). Os debates entre as crianças foram transcritos e transformados em objeto de uma análise de conteúdo do tipo temática, que resultou nas categorias que apresentamos, de modo breve, a seguir:

a) $\mathrm{Na}$ escola, as atividades são monótonas, mecânicas, o tempo não passa, as atividades são repetitivas; se o aluno não entender um conteúdo, o professor não explica de novo, ou de outro modo;

b) "Os professores não estão nem aí para os alunos", os alunos não recebem atenção dos professores, os quais não "prestam atenção se o aluno está aprendendo ou não", os professores não se preocupam com os alunos;

c) Para os alunos mais novos na classe de aceleração, a "aceleração" representa uma esperança de retornarem à sua classe de origem, reencontrarem seus colegas de antes, estando no mesmo nível de aprendizagem, esperança de recuperarem o tempo perdido, de retomarem o "ritmo normal";

d) A escola discrimina os alunos da classe de aceleração, especialmente "os professores que 'olham para nós, como se a gente fosse burro', sua classe é a mais desprovida de material escolar, a mais "destruída";

e) Sem escola não há futuro positivo, "em escola você é um nada", só tem acesso a profissões muito desfavorecidas, "só pode ser faxineira"; 
f) Na classe de aceleração, há um sentimento de estar integrado à turma, pois não se sentem como crianças muito velhas no meio de crianças muito pequenas.

Lopes (2017) aponta que o material projetivo usado nas entrevistas coletivas cria espaço para a emergência espontânea de metáforas, e que, no contexto da discussão, algumas se apresentam como consensuais, à medida que um indivíduo as expressa e outros aderem a elas, reforçando: "A escola é uma prisão, não se pode fazer nada..."; "O recreio é como o banho de sol..."; "Sem escola, você é um NADA..." (em relação ao futuro do aluno); "Os professores olham para agente como se a gente fosse NADA..."; "A escola é como a casa da gente..." (no sentido de serem obrigados a fazer tarefas repetitivas e tediosas).

$\mathrm{Na}$ segunda fase, com o auxílio de uma caixa de figuras e objetos (trem, casa, automóvel, animais, ferramentas etc.), foi feita uma indução de metáforas (se a classe de aceleração fosse alguma dessas coisas, o que seria?). Os resultados apontaram três figuras: o relógio, a tartaruga e a casa, que reforçam as metáforas e os significados encontrados nas discussões espontâneas. Nas discussões induzidas pelos objetos, aparece uma metáfora que condensa e organiza o sentido da experiência na classe de aceleração: "Eles só querem empurrar a gente... [para fora da escola]".

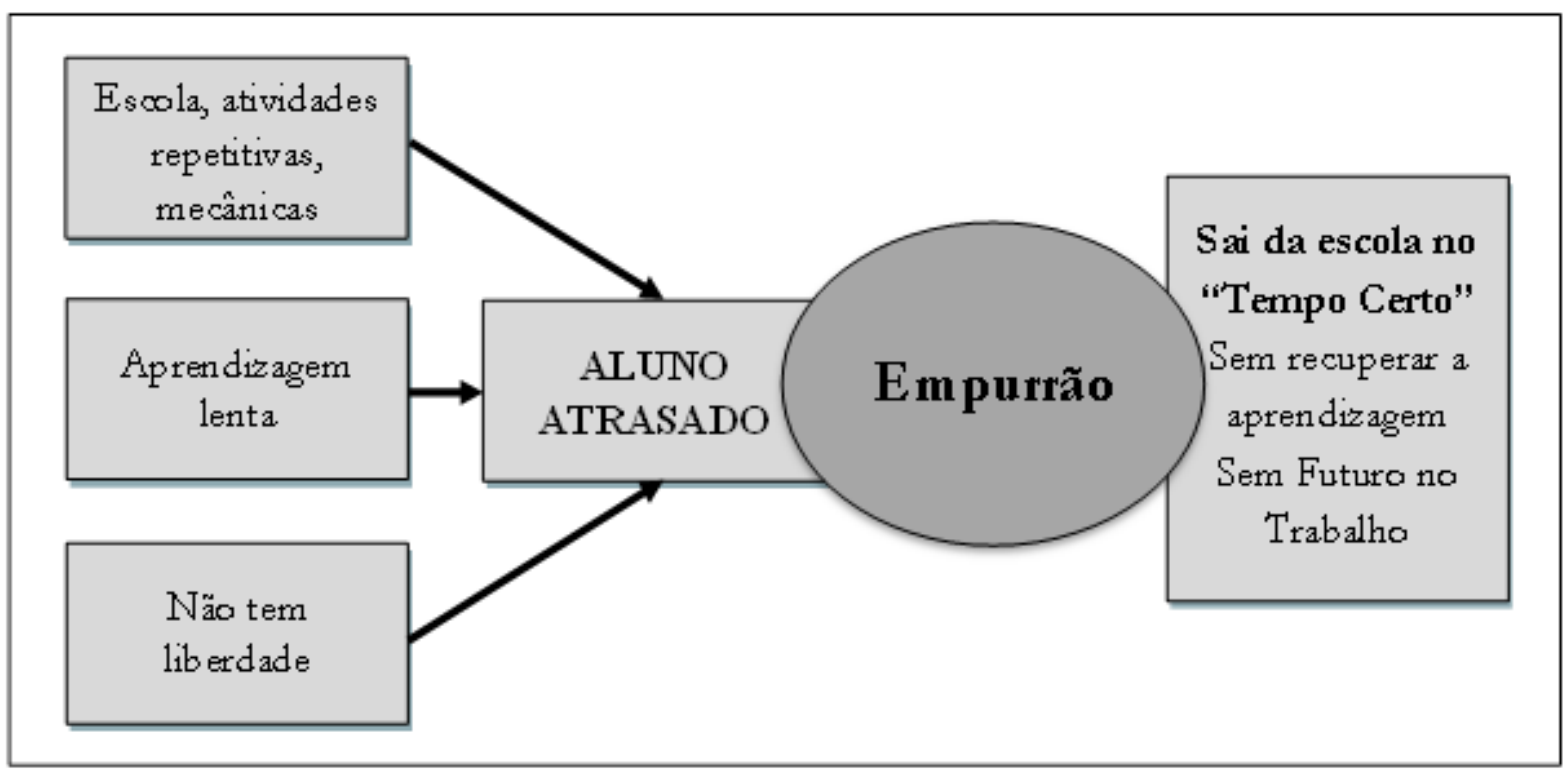

FIGURA 3 - Núcleo figurativo da representação social de classes de aceleração por crianças do Ensino Fundamental

Com base na Figura 3, podemos dizer que a questão pedagógica mais importante não seria somente conhecer como os alunos pensam e sentem a classe de aceleração por meio de um estudo de suas representações. A identificação do núcleo figurativo permite que vejamos dinamicamente a função perversa desse "programa", cuja finalidade não é oferecer condições especiais para a aprendizagem, mas reencaixar artificialmente o aluno com defasagem idade/série no fluxo normal da escola. Também, por sua função figurativa, esse núcleo condensa e aponta os sentimentos em jogo da parte dos sujeitos.

\section{CONSIDERAÇÕES FINAIS}

Recapitulando e sintetizando o que aqui foi apresentado, podemos dizer que há um consenso quanto à formação de uma primeira imagem estabelecida, de fato, selecionada, que é o "núcleo imagístico", com uma função muito própria (estruturante) na gênese das RSs, guiando a relação do grupo com o objeto. Assim, todas as ações e trocas comunicativas são guiadas e tornamse "objeto" de categorização: "isto é o objeto", "isto não é o objeto"; "isto faz parte do objeto", "aquilo não faz parte do objeto"; "esta prática está em acordo com o objeto", "aquela prática não convém, ou é inaceitável, em relação ao objeto". Contudo, esse processo de categorização vai afinar 
(especificar) e consolidar o significado do objeto; então, a imagem-básica é transformada. Esses processos levam-nos a pensar que os "esquemas" encontrados por Moscovici (1976) e Jodelet (1989a) são um tipo de formação cognitiva-social que está entre uma imagem mental, em sentido restrito, e um "esquema conceitual" propriamente dito, sendo que este último pode, sem prejuízo, ser assimilado a um "núcleo central". A consequência dessa reflexão para o estudo da objetivação e das RSs é a necessária e incontornável complementariedade entre a imagem social (herdeira direta do núcleo imagístico, ou núcleo figurativo) e o núcleo central, o que se trata de uma questão ainda a ser mais desenvolvida nos estudos de RS, incluindo as pesquisas que apresentamos neste trabalho.

O que nos parece produtivo é apontar o necessário estudo das imagens sociais de um objeto e sua condensação (ou consolidação) na forma de um núcleo figurativo, para se estudar os aspectos mais afetivos e experienciais da RS para um grupo, bem como ao nível da "microgênese" dos significados (DUVEEN; LLOYD, 1990; GARNIER, 1999). Por outro lado, o conhecimento de um núcleo mais estruturado (núcleo central) seria necessário para uma apreensão mais conceitual e processual (no sentido da dinâmica funcional entre crenças descritivas e prescritivas) e para o estudo da interação entre a RS e a situação concreta e imediata, no sentido das regulações dos metasistemas de pensamento sobre os sistemas cognitivos dos indivíduos e suas práticas.

Tal perspectiva tem consequências para o estudo e a análise do funcionamento de uma RS no interior das dinâmicas sociais, ou ainda para o estudo das dinâmicas internas das RSs em relação com seus contextos, ou ambientes, tanto de um ponto de vista semiótico (como o estudo das relações de produção, negociação e transformação dos significados do objeto representado, em sua interação com as redes ou sistemas simbólicos pré-existentes) quanto de um ponto de vista de orientação das práticas. O estudo do núcleo central, em suas formas clássicas mais linguísticas e cognitivas, "não seria o suficiente para dar conta da função de figuração". Pode-se pensar que um núcleo central seria, como diz Moliner (2005), um receptor geral, flexível, de novas e infinitas imagens. Assim, o estudo da riqueza experiencial e imagística que se aglutina em torno de "significados centrais", em um contínuo movimento de objetivação, solicitaria a identificação e análise do "núcleo figurativo", que, por sua natureza de imagem homogênea à primeira fase de objetivação, seria o caminho mais produtivo. Respondemos, assim, ao problema da falsa questão que diferencia o núcleo figurativo do núcleo central. Embora não sejam a mesma coisa, ambos os núcleos complementam-se nos estudos de RS.

Finalizando, retomamos a intenção primeira deste estudo que foi propor uma reflexão teórica para o campo da Educação embasada na TRS, teoria fundamentada na Psicologia Social. Reafirmamos o potencial dessa teoria para avançarmos com os estudos no campo educacional, na perspectiva de um olhar psicossocial. Pesquisas dessa natureza podem trazer à tona representações em luta sobre objetos do campo educacional, construídas nas interações entre os grupos sociais, potencializando mudanças no contexto em que essas interações emergem. Trata-se, desse modo, de uma via fértil à medida que o aprofundamento do estudo do núcleo figurativo, especialmente sua relação com as metáforas, pode contribuir para pesquisas sobre as relações entre pensamento, práticas sociais e mudanças.

\section{REFERÊNCIAS}

ABDALLA, Maria de Fátima Barbosa; VILLAS BÔAS, Lúcia S. Um olhar psicossocial para a educação. Cadernos de Pesquisa, São Paulo, v. 48, n. 167, p. 14-41, 2018.

ABRIC, Jean-Claude. Jeux, conflits et représentations sociales. Thèse de Doctorat d'État, Université de Provence, Aix-en-Provence, 1976. 
ABRIC, Jean-Claude. Approche théorique et expérimentale des représentations sociales en situation d' interaction. In: FARR, Robert M; MOSCOVICI, Serge (Ed.). Social representations. Cambridge: Cambridge University Press, 1983.

ABRIC, Jean-Claude. Approche théorique et expérimentale des représentations sociales en situation d' interaction. In: FARR, Robert M; MOSCOVICI, Serge (Ed.). Social representations. Cambridge: Cambridge University Press, 1983 apud JODELET, Denise. Représenttion sociale: phénomène, concept et théorie. In: MOSCOVICI, Serge. Psychologie sociale. Paris: Presses Universitaires de France, 1984. p. 369

ABRIC, Jean-Claude. Coopération, compétition et représentations sociales. Cousset: Del Val, 1987.

ABRIC, Jean-Claude. L'étude éxperimentale des représentationns sociales. In: JODELET, D.

(Ed.). Les représentations sociales. Paris: Presses Universitaires de France, 1989. p. 187-203.

ABRIC, Jean-Claude. Pratiques sociales, représentations sociales. In: ABRIC, Jean-Claude (Dir.).

Pratiques sociales et représentations. Paris: Presses Universitaires de France, 1994. p. 217-238.

ANDRADE, Daniela B. da S. F. Se a escola pudesse ser outra coisa, que coisa ela seria? In: V Jornada Internacional e III Conferência Brasileira sobre Representações Sociais. Brasília, DF, 2007.

APOSTOLIDIS, Thémis. Représentation d'autrui et relations intimes: remarques topologiques sur les croyances. Psychologie et Société, v. 5, n. 3, p. 13-42, 2002.

ARRUDA, Angela. Qu'est-ce qui fait du Brésil le Brésil? Imaginaire, croyances et représentations sociales, Psychologie \& Société, v. 5, n. 3, p. 43-60, 2002.

BARDIN, Laurence. Análise de conteúdo. Lisboa: Edições 70, 2000.

BARTHES, Roland. L'aventure sémiologique. Paris: Editions du Seuil, 1985.

BILLIG, Michael. Ydeology and opinions. London: SAGE Publications Ltd, 1991.

BILLIG, Michael. Argumentando e pensando. Petrópolis: Editora VOZES, 1996.

BONARDI, Christine; ROUSSIAU, Nicolas. Les représentations sociales. Paris: Dunod, 1999. 
BOUDON Raymond. The logic of social action. London: Routledge \& Kegan, 1990.

CHOMBART-DE- LAUWE, Marie-Jose. Un monde autre: l’Enfance. Paris: Payot, 1971.

CHOMBART-DE- LAUWE, Marie-Jose. Liens entre les représentations véhiculées sur l'enfant et les représeentations intériorisées par les enfants. In: DOISE, Willem; PALMONARI, Alberto (Ed.). Les représentations sociales. Paris: Delachaux et Niestlé S.A., Neuchâtel (Switzerland), 1986. p. 96-117.

DUVEEN, Gerard; LLOYD, Barbara. Introduction. In: DUVEEN, Gerard; LLOYD, Barbara (Ed.). Social representations and the development of knowledge. Cambridge: Cambridge University Press, 1990.

ECO, Umbeerto. Le signe. Bruxelles: Editions Labor, 1988.

ELEJABARRIETA, Fran. Le concept de représentation sociales. In: DESCHAMPS, JeanClaude; BEAUVOIS, Jean-Leon (Ed.) Des attitudes aux atributions. Grenoble: Presses Universitaires de Grenoble, 1996. p. 137-150.

ELEJABARRIETA, Fran; VALENCIA, Jorge; WAGNER, Wolfgang. The personification effect: a way of objectivation of the unfamiliar in the social representation of sexual infidelity. General Meeting of European Association of Experimental Social Psychology, Lisboa, 1993.

FLAMENT, Claude. Structure et dynamique des représentations sociales. In: JODELET, Denise (Ed.). Les représentations sociales. Paris: Presses Universitaires de France, 1989. p. 204-219.

FLAMENT, Claude. Aspects périphériques des représentations sociales. In: GUIMELLI, Christian (Ed.). Structures et transformations des représentations sociales. Lausanne: Delachaux et Niestlé, 1994. p. 85-118.

FLAMENT, Claude; ROUQUETTE, Michel-Louis. Anatomie des idées ordinaires. Paris: Armand-Colin, 2003.

GARNIER, Catherine. La genèse des représentations sociales dans une perspective developpementale. In: ROUQUETTE, Michel-Louis \& GARNIER, Cathérine (Ed.). La genèse des représentations sociales. Montreal: Editons Nouvelles, 1999. p. 87-114. 
HEIDER, Fritz. Ding und medium. Symposium, v. 1, p. 109-158, 1927.

JODELET, Denise. Représenttion sociale: phénomène, concept et théorie. In: MOSCOVICI, Serge. Psychologie sociale. Paris: Presses Universitaires de France, 1984.

JODELET, Denise. Fou et folie dans un milieu rural français: une approche monographique. In: DOISE, Willem; PALMONARI, Augusto (Ed.). Les représentations sociales. Neuchâtel (Switzerland), Paris: Delachaux et Niestlé S. A., 1986. p. 171-192.

JODELET, Denise. Représentations sociales. Un domaine en expansion. In: JODELET, D. (Ed.). Les représentations sociales. Paris: Presses Universitaires de France, 1989.

JODELET, Denise. Folies et représentations sociales. Paris: Presses Universitaires de France, 1989a.

JODELET, Denise. Loucuras e representações sociais. 2. ed. Petrópolis: Vozes, 2015.

KALAMPALIKIS, Nikos. Représentations et mythes contemporains. Psychologie \& Société, v. 5, n. 3, 2002.

KALAMPALIKIS, Nikos; APOSTOLIDIS, Thémis. La perspective sociogénétique des représentations sociales. In: LO MONACO, Grégory; DELOUVEE, Sylvain; RATEAU, Patrick. Les représentations sociales: Théories, méthodes et applications. Louvain-la-Neuve: De Boeck Supérieur, 2016. p. 69-77.

LAKOFF, George; JOHNSON, Mark. Metáforas da vida cotidiana. Campinas: Mercado das Letras, 2002.

LOPES, Marianna J. S. Representações sociais de escola elaboradas por alunos que frequentam "salas de aceleração". 2017. 131 f. Dissertação (Mestrado em Educação) Universidade Estácio de Sá, Rio de Janeiro, Brasil, 2017.

MAZZOTTI, Tarso B. Investigando os núcleos figurativos como metáforas. In: I Jornada Internacional sobre Representações Sociais. Natal-RN, 1998. p. 1-12. CD-ROM.

MAZZOTTI, Tarso B. Metáfora: figura argumentativa central na coordenação discursiva das representações sociais. In: CAMPOS, Pedro Humberto F.; LOUREIRO, Marcos C. da S. (Org.). Representações sociais e práticas educativas. Goiânia: UCG, 2003. p. 89-102. 
MAZZOTTI, Tarso B. A exposição do implícito nas representações sociais. In: VI Simpósio Estadual de Representações Sociais e Educação (VI SERS) e I Simpósio Internacional de Representações Sociais, Educação e Subjetividade (I SIERS). Salvador, 2016.

MOLINER, Pascal. La représentation sociale comme grille de lecture. Aix-en-Provence: Publications de l'Université de Provence,1992.

MOLINER, Pascal. Les méthodes de répérage et d'identification du noyau des représentations sociales. In: GUIMELLI, Christian (Ed.). Structures et transformations des représentations sociales. Lausanne: DELACHAUX et NIESTLE, 1994. p. 199-231.

MOLINER, Pascal. A two dimensional modelo of social representations. European Journal of Social Psychology, v. 25, n. 1, p. 27-40, 1995.

MOLINER, Pascal. Noyau central, principes organisateurs et modèle bi-dimensionnel des représentations sociales. "Vers une intégration théorique?". Cahiers Internationaux de Psychologie Sociale, v. 28, n. 12, p. 44-55, 1995 a.

MOLINER, Pascal. Images et représentations sociales: de la théorie des représentations à l'étude des images sociales. Grenoble: PUG, 1996.

MOLINER, Pascal. La fonction generatrice du noyau des représentations sociales: Une remise en cause? Papers on Social Representations, v. 14, p. 3.1-3.14, 2005.

MOLINER, Pascal. Psychologie sociale de 1'image. Grenoble: PUG, 2016.

MOSCOVICI, Serge. La psychanalyse, son image et son public. Paris: Presses Universitaires de France, 1961.

MOSCOVICI, Serge. La psychanalyse, son image et son public. Paris: Presses Universitaires de France, 1976.

MOSCOVICI, Serge. A representação social da psicanálise. Tradução de Álvaro Cabral. Rio de Janeiro: Zahar, 1978.

MOSCOVICI, Serge. The phenomenon of social representations. In: FARR, Robert M; MOSCOVICI, Serge (Ed.). Social representations. Cambridge: Cambridge University Press, 1983. 
MOSCOVICI, Serge. Representações Sociais: Investigações em Psicologia Social. Tradução de Pedrinho A. Guareschi. Petrópolis: Vozes, 2003.

MOSCOVICI, Serge. A Psicanálise, sua imagem e seu público. Tradução de Sonia Fuhrmann. Petrópolis: Vozes, 2012.

MOSCOVICI, Serge; HEWSTONE, Miles. De la science au sens commun. In: MOSCOVICI, Serge. Psychologie sociale. Paris: PUF, 1984. p. 539-566.

ORDAZ, Olga; VALA, Jorge. Objetivação e ancoragem das representações de suicídio na imprensa escrita. Análise Social, v. XXXII, 1997.

RATEAU, Patrick; MOLINER, Pascal; GUIMELLI, Christian; ABRIC, Jean-Claude. Social Representations Theory. In: VAN LANGE, Paul A. M.; KROGLANSKI, Arie W.; HIGGINS, E. Tory (Org.). Handbook of theories of social psychology, London: SAGE Publications Ltd, v. 2, p. 477-497, 2012.

SANTOS, Ivan S. dos. Representações sociais de Unidades de Polícia Pacificadora (UPP) por professores de escolas públicas no município do Rio de Janeiro e seus efeitos no entorno escolar. 2016. 188 f. Tese (Doutorado em Educação) - Universidade Estácio de Sá, Rio de Janeiro, Brasil, 2016.

SOUSA, Clarilza P. de. Estudos de representações sociais em educação. Psicologia da Educação: Revista do Programa de Estudos Pós-Graduados em Psicologia da Educação/Pontifícia Universidade Católica de São Paulo, São Paulo: EDUC, n. 1, p. 285- 323, dez. 2002.

SOUSA, Clarilza P. de; TAVARES, Marialva R.; VILLAS BÔAS, Lúcia P. S. Apresentação do estudo: representações sociais sobre o trabalho docente. In: SOUZA, Clarilza P. de; PARDAL, Luis A.; VILLAS BÔAS, Lúcia P. S. (Org.). Representações sociais sobre o trabalho docente. Aveiro: Universidade de Aveiro, 2009. p. 15-30.

SOUSA, Clarilza P. de; VILLAS BÔAS, Lúcia P. S. A teoria das representações sociais e o estudo do trabalho docente: os desafios de uma pesquisa em rede. Diálogo Educacional, v. 11, n. 33, p. 271-286, 2011.

SOUSA, Clarilza P. de; VILLAS BÔAS, Lúcia P. S. Los estúdios de representaciones sociales y lós desafios para la investigación em educación. In: SEIDMANN, Susana; SOUSA, Clarilza P. de (Org.). Hacia una psicología social de la educación. Buenos Aires: Teseo, 2011a. 
WAGNER, Wolfgang; ELEJABARRIETA, Fran; LAHNSTEINER, Ingrid. How de sperm dominates the ovum: objectification by metaphor in the social representation of conception. European Journal of Social Psychology, n. 25, n. 6, p. 671-688, 1995.

\section{NOTAS}

${ }^{1} \mathrm{O}$ símbolo da barra oblíqua (/), utilizado nas entradas de referência, no texto, significa que o primeiro ano refere-se à primeira edição na língua de origem, e o segundo ano, à edição em português, mais utilizada no texto.

2 A expressão "núcleo imagístico" é usada tanto por Jodelet (1984) quanto por Abric (1987), como sinônimo de "núcleo figurativo", reforçando sua natureza originária de imagem.

Submetido: $05 / 06 / 2018$

Aprovado: 12/09/2019

\section{Contato:}

Rita de Cássia Pereira Lima Av. Presidente Vargas, 642, $22^{\circ}$ andar, Cobertura

Rio de Janeiro $|\mathrm{RJ}|$ Brasil CEP 20.071-001 